\title{
ADUBAÇÃO FOSFATADA NO CRESCIMENTO INICIAL E NA NUTRIÇÃO DE MUDAS DE PINHÃO-MANSO ${ }^{(1)}$
}

\author{
Mariângela Brito Freiberger ${ }^{(2)}$, Iraê Amaral Guerrini ${ }^{(3)}$, Gustavo Castoldi ${ }^{(2)}$ \& Laerte $^{2}$ \\ Gustavo Pivetta ${ }^{(2)}$
}

\begin{abstract}
RESUMO
O pinhão-manso (Jatropha curcas $\mathrm{L}$.) é uma espécie oleaginosa perene que tem despertado interesse econômico para produção de biodiesel. A fim de viabilizar o cultivo dessa espécie, é fundamental determinar, entre outras coisas, as suas demandas nutricionais. Objetivou-se avaliar o crescimento inicial e a nutrição mineral do pinhão-manso, bem como a fertilidade do solo em razão da adubação fosfatada. O estudo foi desenvolvido sob estufa plástica, em delineamento experimental de blocos casualizados com quatro repetições. As plantas foram cultivadas em vasos plásticos preenchidos com $50 \mathrm{dm}^{3} \mathrm{de}$ um Latossolo Vermelho. Foram avaliadas as doses de 0, 50, 100, 150 e $200 \mathrm{mg} \mathrm{dm}^{-3} \mathrm{P}$, além de um tratamento-controle. Mensalmente, realizou-se a avaliação da altura e do diâmetro de colo das mudas. $\mathrm{O}$ estudo foi encerrado 150 dias após o transplantio das mudas, quando se determinaram a área foliar, a massa de matéria seca, os teores foliares e o acúmulo total de macro ( $\mathrm{N}, \mathrm{P}, \mathrm{K}, \mathrm{Ca}, \mathrm{Mg}$ e $\mathrm{S})$ e micronutrientes ( $\mathrm{B}, \mathrm{Cu}, \mathrm{Fe}, \mathrm{Mn}$ e $\mathrm{Zn}$ ), além dos atributos químicos do solo. A ausência somente da adubação fosfatada é tão limitante ao crescimento inicial do pinhão-manso quanto a ausência simultânea da adubação e correção do solo. A dose de $57 \mathrm{mg} \mathrm{dm}^{-3}$ de $P$ pode ser indicada para o crescimento inicial do pinhãomanso. $\mathrm{O}$ acúmulo total de nutrientes nas mudas de pinhão-manso apresentou a seguinte ordem: $\mathrm{K}>\mathrm{N}>\mathrm{Mg}>\mathrm{Ca}>\mathrm{P}>\mathrm{S}>\mathrm{Fe}>\mathrm{Mn}>\mathrm{B}>\mathrm{Zn}>\mathrm{Cu}$. A adubação fosfatada promoveu aumento da capacidade de troca de cátions do solo (CTC).
\end{abstract}

Termos para indexação: Jatropha curcas, área foliar, massa de matéria seca, macronutrientes, micronutrientes.

(1) Parte da Dissertação de Mestrado da primeira autora apresentada ao Programa de Pós-Graduação em Ciência Florestal da Faculdade de Ciências Agronômicas - FCA/UNESP. Recebido para publicação em 16 de agosto de 2012 e aprovado em 25 de setembro de 2013.

(2) Doutoranda(o) em Agronomia (Agricultura), FCA/UNESP. Caixa Postal 237. CEP 18610-307 Botucatu (SP). E-mail: maia_bf@yahoo.com.br, castoldi@fca.unesp.br, lgpivetta@fca.unesp.br

(3) Professor Titular, Departamento de Recursos Naturais/Ciência do Solo, FCA/UNESP. Bolsista CNPq. E-mail: iguerrini@fca.unesp.br 


\title{
SUMMARY: PHOSPHORUS FERTILIZATION ON THE EARLY GROWTH AND NUTRITION OF PHYSIC NUT SEEDLINGS
}

\begin{abstract}
Physic nut (Jatropha curcas L.) is a perennial oilseed species that has aroused economic interest for biodiesel production. Among other factors, it is essential to determine the nutritional demands of this species to facilitate raising it as a crop. This study aimed to evaluate the early growth and mineral nutrition of physic nut, as well as soil fertility, as affected by phosphorus fertilization. The study was carried out in a plastic greenhouse in a completely randomized block experimental design with four replicates. The plants were grown in plastic pots filled with $50 \mathrm{dm}^{3}$ of Latossolo Vermelho (Rhodic Hapludox). Application rates of 0, 50, 100, 150 and $200 \mathrm{mg} \mathrm{dm}^{-3}$ of $P$ were tested, plus a control. Evaluations of plant height and root collar diameter were performed monthly. The experiment was ended 150 days after transplant of the seedlings, at which time leaf area, dry weight, leaf contents and total accumulation of macro$(N, P, K, C a, M g$ and $S$ ) and micronutrients (B, $\mathrm{Cu}, \mathrm{Fe}, \mathrm{Mn}$ and $\mathrm{Zn}$ ) were performed, and soil chemical properties were analyzed. We concluded that absence of $P$ fertilization alone is as limiting to early growth of physic nut as simultaneous absence of soil amendment and fertilization. The rate of $57 \mathrm{mg} \mathrm{dm^{-3 }}$ of $P$ may be recommended for initial growth of physic nut. The total accumulation of nutrients in physic nut seedlings exhibited the following order: $K>N>M g>C a>P>S>F e>M n>B>Z n>C u$. Phosphorus fertilization resulted in increased soil cation exchange capacity (CEC).
\end{abstract}

Index terms: Jatropha curcas, leaf area, dry matter, macronutrients, micronutrients.

\section{INTRODUÇÃO}

O pinhão-manso (Jatropha curcas L.) é uma espécie perene nativa da América tropical (Nuñez-Colín \& Goytia-Jiménez, 2009) cujo óleo de suas sementes pode ser utilizado para fins carburantes (Arruda et al., 2004). Com o melhoramento genético e os estudos para aprimorar as práticas de manejo, a espécie poderá ser incluída na produção comercial de biodiesel no Brasil (Laviola \& Dias, 2008; Bhering et al., 2012; Fernandes et al., 2013). Além de ser alternativa para substituir combustíveis fósseis, o pinhão-manso também apresenta capacidade de incrementar carbono similarmente às florestas naturais. $\mathrm{O}$ estoque de carbono no terceiro ano de seu cultivo está próximo a $4,18 \mathrm{Mg} \mathrm{ha}^{-1} \mathrm{C}$ (Torres et al., 2011).

O cultivo de pinhão-manso promove elevada extração de nutrientes do solo, e, portanto, o manejo da adubação da espécie exige atenção (Laviola \& Dias, 2008). O suprimento inadequado de nutrientes, seja falta ou excesso, pode provocar restrições ao crescimento das plantas e alterar relações entre biomassa aérea e radicular, bem como promover alterações entre estádios vegetativos e reprodutivos (Buwalda \& Goh, 1982; Mengel, 1983; Marschner, 1995; Peng et al., 1993). As limitações na disponibilidade de fósforo $(\mathrm{P})$ no início do ciclo vegetativo das culturas podem resultar em restrições no desenvolvimento delas, fazendo com que não haja recuperação da planta posteriormente, mesmo aumentando o suprimento de $\mathrm{P}$ em níveis adequados (Jeschke et al., 1996; Roggatz et al., 1999).

O pinhão-manso apresenta alta taxa de crescimento e o P é limitante na fase inicial de desenvolvimento, sendo altamente exigido para o desenvolvimento do sistema radicular e a formação de folhas e frutos (Laviola \& Dias, 2008). O fornecimento de $\mathrm{P}$ nos primeiros anos de cultivo de espécies perenes deve ser em maior quantidade que o acumulado pela planta, pois, além de os solos brasileiros apresentarem baixo teor natural de $\mathrm{P}$, esse nutriente é rapidamente fixado pela fração argila, constituída principalmente por óxidos de $\mathrm{Fe}$ e $\mathrm{Al}$ (Novais \& Smyth, 1999).

Silva et al. (2009) estudaram o efeito da omissão de nutrientes em mudas de pinhão-manso e concluíram que a omissão de $\mathrm{P}$ reduziu em 68 \% a produção de massa de matéria seca total das plantas. Souza et al. (2011) constataram que mudas de pinhãomanso com 120 dias responderam à adubação fosfatada, recomendando a dose de $55 \mathrm{mg} \mathrm{dm}^{-3} \mathrm{de} \mathrm{P}$ para o crescimento inicial da espécie. Prates et al. (2013) verificaram que a adubação fosfatada promoveu incrementos de altura, diâmetro, área foliar, matéria fresca da raiz, parte aérea e total de mudas de pinhãomanso com 60 dias. Lima et al. (2011a) observaram que, além de favorecer o incremento de raiz e área foliar, a adubação fosfatada promoveu aumento do teor de todos os macronutrientes (exceto $\mathrm{Ca}$ ) na parte aérea de mudas de pinhão-manso.

Apesar de alguns estudos apresentarem resultados importantes com relação à adubação fosfatada para o desenvolvimento inicial do pinhão-manso, é preciso aprimorar as pesquisas visando recomendar a dose adequada de P para a produção de mudas dessa espécie. Além disso, faz-se necessário apurar o comportamento dos nutrientes na planta e no solo, mediante fornecimento da adubação fosfatada. Diante do exposto, objetivou-se, com este estudo, verificar o efeito de doses de P na fertilidade do solo, no desenvolvimento inicial e no estado nutricional de mudas de pinhãomanso. 


\section{MATERIAL E MÉTODOS}

O experimento foi realizado sob estufa plástica no Departamento de Recursos Naturais/Ciência do Solo da Faculdade de Ciências Agronômicas (FCA), UNESP, em Botucatu, SP. Durante o período experimental, as temperaturas máxima e mínima foram respectivamente de 41 e $21{ }^{\circ} \mathrm{C}$. Avaliaram-se cinco doses de P: 0, 50, 100, 150 e $200 \mathrm{mg} \mathrm{dm}^{-3}$, denominados respectivamente de $\mathrm{P}_{0}, \mathrm{P}_{50}, \mathrm{P}_{100}, \mathrm{P}_{150} \mathrm{e}$ $\mathrm{P}_{200}$, além de um tratamento-controle. Utilizou-se o delineamento de blocos casualizados com quatro repetições. Cada unidade experimental foi composta por um vaso plástico de $60 \mathrm{dm}^{3}$ preenchido com $50 \mathrm{dm}^{3}$ de Latossolo Vermelho, textura média arenosa (Embrapa, 2006), contendo uma muda de pinhãomanso.

As mudas foram produzidas no viveiro da FCA a partir de sementes de genótipos superiores da Embrapa Semi-Árido e desenvolveram-se em tubetes de $116 \mathrm{~cm}^{3}$ preenchidos com substrato comercial Carolina ${ }^{\circledR}$ (turfa, cascas de arroz carbonizadas e vermiculita), em casa de germinação. A fase de produção de mudas durou 45 dias e, para o transplantio nos vasos, essas foram selecionadas em razão do padrão de desenvolvimento, de modo que as mudas selecionadas apresentavam altura média de $15 \mathrm{~cm}$, diâmetro médio de $0,8 \mathrm{~cm}$, uma folha expandida e outra em início de desenvolvimento.

A análise dos atributos químicos e físicos do solo antes do estudo apresentou os seguintes resultados: 289, 56 e $655 \mathrm{~g} \mathrm{dm}^{-3}$ de argila, silte e areia, respectivamente; $\mathrm{pH}\left(\mathrm{CaCl}_{2}\right): 4,0$; matéria orgânica (MO): $26 \mathrm{~g} \mathrm{dm}^{-3}$; $\mathrm{P}_{\text {resina }}$ : 8,0 $\mathrm{mg} \mathrm{dm}^{-3}$; e $\mathrm{K}, \mathrm{Ca}, \mathrm{Mg}$, soma de bases (SB) e CTC: 0,2; 2,0; 1,0; 3,0; e 76 mmol $_{c}$ $\mathrm{dm}^{-3}$, respectivamente. A saturação por bases inicial do solo era $3 \%$ e foi corrigida para $60 \%$ por meio da incorporação de 112,8 g de calcário dolomítico (29 \% de $\mathrm{CaO}, 18 \%$ de $\mathrm{MgO}$ e PRNT de $96 \%$ ) por vaso. O P na forma de superfosfato triplo $(17,9 \% \mathrm{P})$ foi incorporado ao solo 40 dias após a incubação com o calcário. À exceção do tratamento-controle - $\mathrm{P}_{0}$, que não recebeu adubação e nem calcário, os demais tratamentos receberam adubação com $80 \mathrm{mg} \mathrm{dm}^{-3} \mathrm{~N}$ na forma de ureia ( $45 \%$ de N), $80 \mathrm{mg} \mathrm{dm}^{-3} \mathrm{~K}$ na forma de cloreto de potássio $\left(60 \%\right.$ de $\left.\mathrm{K}_{2} \mathrm{O}\right)$ e micronutrientes, em g/vaso: 0,59 de sulfato manganoso (26\% de $\mathrm{Mn}$ ); 0,95 de sulfato de zinco (23\% de Zn); e 0,24 de ácido bórico (17\% B), de acordo com a recomendação de Novais et al. (1991) para adubação básica de solo. A homogeneização do corretivo e, posteriormente, dos fertilizantes com o solo, foi realizada em betoneira.

Por ocasião do transplantio das mudas, que ocorreu no início de outubro de 2010, realizaram-se as avaliações de diâmetro de colo, utilizando-se paquímetro digital, e altura, usando-se régua graduada. Nos dois primeiros meses de condução do experimento, essas avaliações foram realizadas quinzenalmente e, a partir do terceiro mês, mensalmente. Ao longo do estudo, os vasos foram irrigados diariamente mantendo-se a umidade do solo próxima a $70 \%$ da capacidade de campo, conforme descrito por Ramos Júnior et al. (2013). A avaliação final foi realizada 150 dias após o transplantio (DAT) das mudas, quando todas as folhas foram destacadas para determinação da área foliar no medidor Area Meter (Modelo LICOR LI-3000). Cada planta foi dividida em folhas, caule, pecíolos e raiz, partes essas que foram acondicionadas em sacos de papel, e secas em estufa com circulação de ar a $60{ }^{\circ} \mathrm{C}$ até massa seca (MS) constante.

O material vegetal seco foi pesado, moído em moinho Willey e amostrado para quantificação dos teores de macro (N, P, K, Ca, $\mathrm{Mg}$ e S) e micronutrientes (B, $\mathrm{Cu}, \mathrm{Fe}, \mathrm{Mn}$ e $\mathrm{Zn}$ ), conforme descrito em Malavolta et al. (1997). O acúmulo de nutrientes foi determinado pela multiplicação da MS total (em g) pelo teor total de cada nutriente e posterior divisão por 1.000, obtendo-se o resultado em g e mg para macro e micronutrientes, respectivamente. A quantidade total de cada nutriente absorvido pela planta foi obtida pelo somatório das quantidades acumuladas em cada parte da planta.

Com trado tipo sonda aberto, coletaram-se três amostras de solo em cada vaso, perfazendo uma amostra composta. $\mathrm{O}$ solo foi seco e peneirado em malha 2,0 mm para análise de $\mathrm{pH}, \mathrm{MO}, \mathrm{P}_{\text {resina }}, \mathrm{H}+\mathrm{Al}$, $\mathrm{K}, \mathrm{Ca}, \mathrm{Mg}, \mathrm{B}, \mathrm{Cu}, \mathrm{Fe}, \mathrm{Mn}$ e Zn, de acordo com Raij et al. (2001), calculando-se posteriormente a SB (soma de bases), CTC e saturação por bases (V\%).

Os valores de altura e diâmetro de colo de cada uma das avaliações foram submetidos à análise de variância e comparados pelo teste de Tukey a $5 \%$. Os dados das avaliações finais, à exceção do tratamentocontrole, foram submetidos à análise de regressão e ajustados a equações polinomiais (linear ou quadrática) ou exponencial do tipo "Rise to Max", em função da significância dos parâmetros de regressão, do valor de $\mathrm{F}$ e do coeficiente de determinação ajustado $\left(\mathrm{R}^{2}\right)$. Quando do uso da equação exponencial, admitiu-se como dose adequada (a partir da qual o aumento do valor de y não justifica o aumento da dose) aquela que propiciou um valor de "y" equivalente a $90 \%$ do valor absoluto da amplitude entre " $y_{0}$ " e "y máx".

\section{RESULTADOS}

A partir dos 15 DAT tanto a altura quanto o diâmetro das plantas de pinhão-manso apresentaram diferenças em razão da adubação fosfatada. Essas diferenças ocorreram por causa do tratamento-controle apresentar médias inferiores que não diferiram do tratamento $\mathrm{P}_{0}$. A diferença desses dois tratamentos em relação aos demais ficou mais pronunciada a partir dos 60 DAT (Figuras 1a e 2b). Os dados de altura, 
diâmetro de colo e área foliar da última avaliação ajustaram-se a modelos exponenciais cujas doses adequadas foram estimadas em 25,48 , e $57 \mathrm{mg} \mathrm{dm}^{-3}$ de $\mathrm{P}$ e correspondem, respectivamente, aos valores calculados de $77 \mathrm{~cm}, 31 \mathrm{~mm}$ e $5,1 \mathrm{~cm}^{2}$ (Figura $2 \mathrm{a}, \mathrm{b}, \mathrm{c})$.

As massas de matéria seca (MSs) de folhas (Figura 3a), caule+pecíolo (Figura 3b), raízes (Figura 3c), bem como a total (Figura 3d) ajustaramse a modelos polinomiais, dos quais se estimou, respectivamente, que 30,62, 20 e 112 g representam $90 \%$ da produção máxima. As doses estimadas de $\mathrm{P}$ que correspondem aos respectivos resultados são 56, 29,51 e $42 \mathrm{mg} \mathrm{dm}^{-3} \mathrm{P}$.

Uma vez que se ajustaram as equações quadráticas, os máximos teores foliares de $\mathrm{P}$ e $\mathrm{Mg}$ (Quadro 1), estimados nessa ordem em 2,1 e 24,6 $\mathrm{g} \mathrm{kg}^{-1}$, foram obtidos, respectivamente, com as doses calculadas de 150 e $136 \mathrm{mg} \mathrm{dm}^{-3} \mathrm{P}$. O teor foliar de $\mathrm{N}\left(33,1 \mathrm{~g} \mathrm{~kg}^{-1}\right)$, assim como o de $\mathrm{Cu}\left(6,2 \mathrm{mg} \mathrm{kg}^{-1}\right)$, não variou em razão da adubação fosfatada (Quadro 1). Os teores de $10,8 \mathrm{~g} \mathrm{~kg}^{-1}$ para o $\mathrm{K}$, de $15,8 \mathrm{~g} \mathrm{~kg}^{-1}$ para o $\mathrm{Ca}$, de $1,8 \mathrm{~g} \mathrm{~kg}^{-1}$ para o $\mathrm{S}$, de $126,2 \mathrm{mg} \mathrm{kg}^{-1}$ para o Fe, de $111,7 \mathrm{mg} \mathrm{kg}^{-1}$ para o Mn e de 21,0 $\mathrm{mg} \mathrm{kg}^{-1}$ para o $\mathrm{Zn}$ representaram $90 \%$ de seus teores máximos e foram
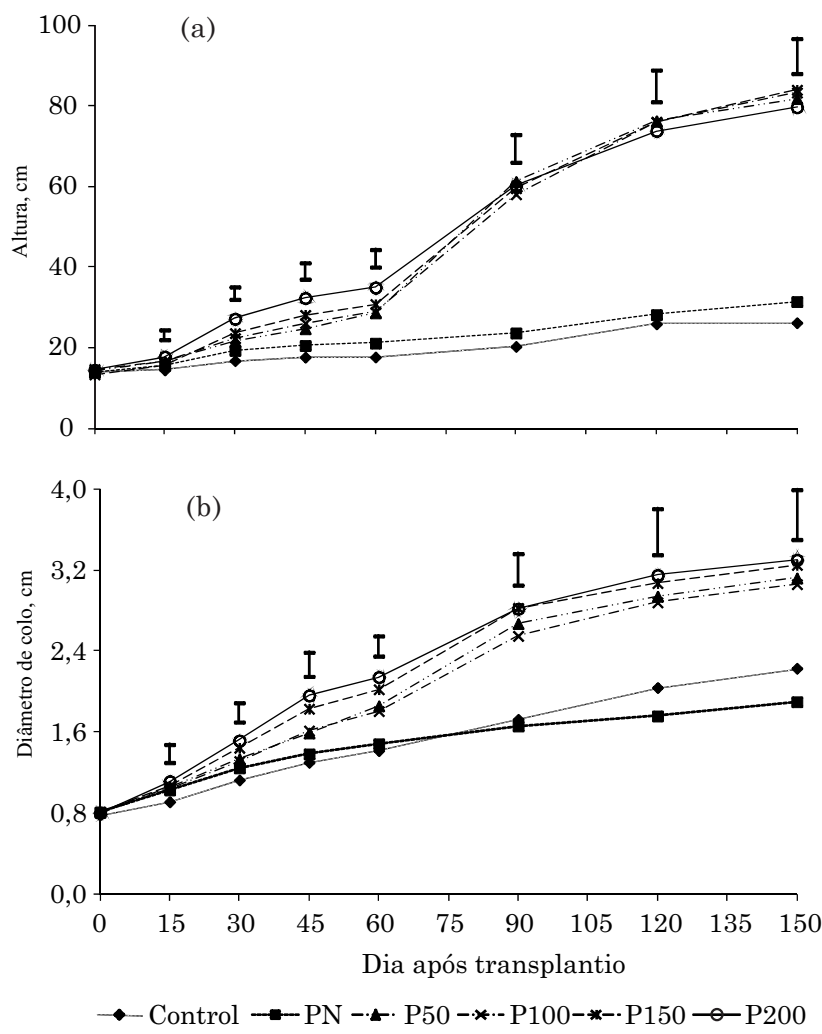

Figura 1. Altura (a) e diâmetro de colo (b) de plantas de pinhão-manso em função de doses de fósforo ao longo de 150 dias após transplantio. Barras verticais indicam o valor de DMS pelo teste Tukey a $5 \%$. estimados com as respectivas doses de P: 48; 45; 86; $51 ; 52$ e $37 \mathrm{mg} \mathrm{dm}^{-3}$. Entretanto, o máximo teor foliar de B (80,0 $\left.\mathrm{mg} \mathrm{kg}^{-1}\right)$ foi verificado com a dose $0 \mathrm{mg} \mathrm{dm}^{-3}$ $\mathrm{P}\left(\mathrm{P}_{0}\right)$, uma vez que seu teor decresceu linearmente quando do aumento das doses de $\mathrm{P}$ (Quadro 1).

$\mathrm{O}$ acúmulo de macro (N, P, K, Ca, Mg e $\mathrm{S})$ e o de micronutrientes (B, Cu, Fe, Mn e Zn) (Quadro 2) apresentou comportamento similar ao de MS total (Figura 3d). O acúmulo de todos os nutrientes ajustouse a modelos exponenciais (Quadro 2), e os valores, em g/planta, de 1,8 para $\mathrm{N}$, de 0,2 para $\mathrm{P}$, de 0,9 para
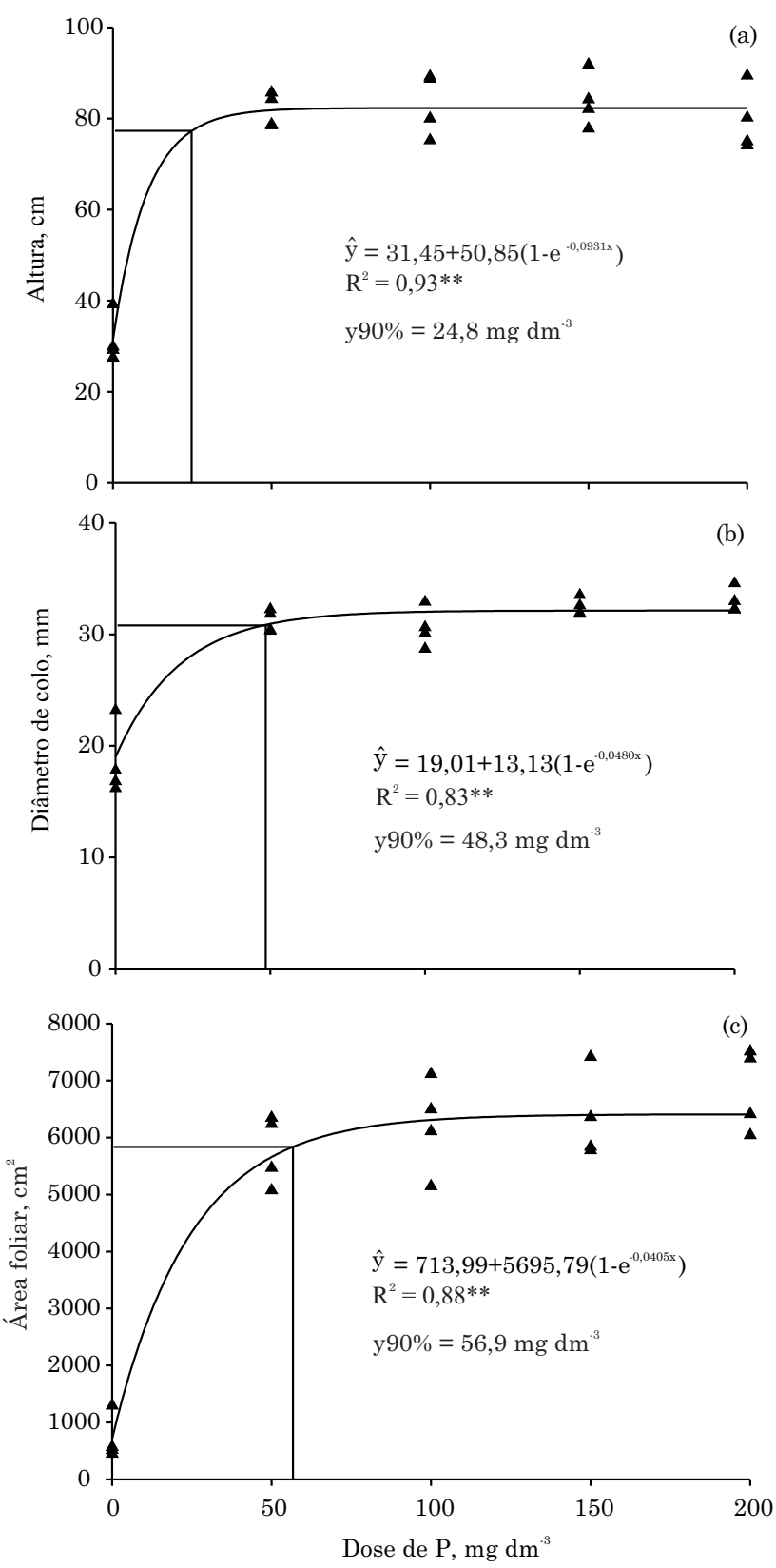

Figura 2. Altura (a), diâmetro de colo (b) e área foliar (c) de plantas de pinhão-manso em função de doses de $\mathrm{P}, 150$ dias após o transplantio. ** significativo a $1 \%$. 

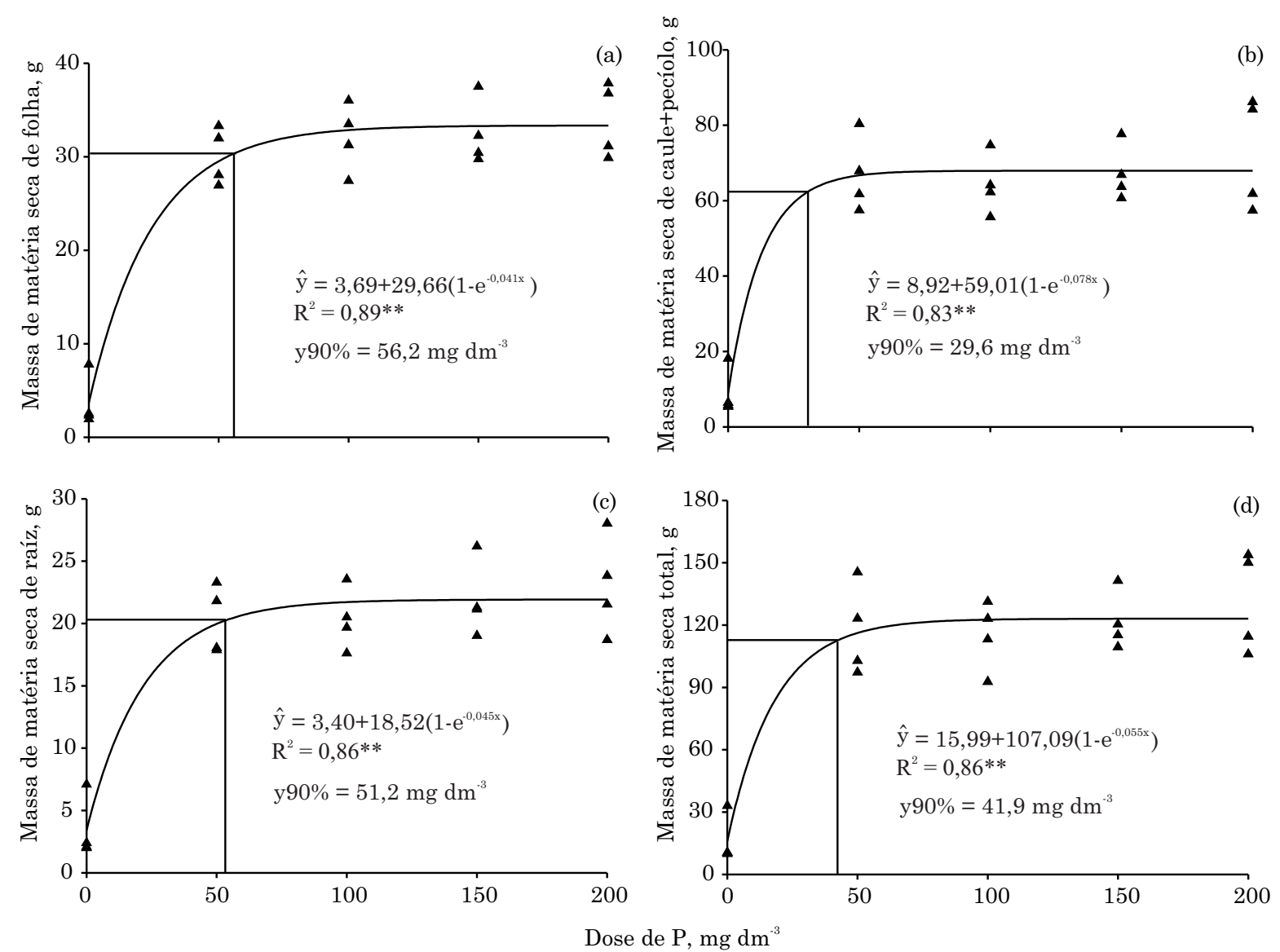

Figura 3. Massa de matéria seca de folhas (a), de caule+pecíolo (b), de raízes (c) e total (d) de plantas de pinhão-manso em função de doses de fósforo, 150 dias após o transplantio. ** significativo a $1 \%$.

Quadro 1. Equações de regressão referentes às concentrações de $\mathrm{N}, \mathrm{P}, \mathrm{K}, \mathrm{Ca}, \mathrm{Mg}$ e S (g kg-1) e B, $\mathrm{Cu}, \mathrm{Fe}$, Mn e $\mathrm{Zn}$ (mg kg-1) em folhas de pinhãomanso em função de doses de $\mathrm{P}, 150$ dias após o transplantio

\begin{tabular}{cll}
\hline Nutriente & \multicolumn{1}{c}{ Equação } & \multicolumn{1}{c}{$\mathbf{R}^{2}$} \\
\hline $\mathrm{N}^{(1)}$ & $\hat{y}=\bar{y}=33,05$ & - \\
$\mathrm{P}^{(2)}$ & $\hat{y}=1,32+0,0098 \mathrm{x}-3,2593 \mathrm{E}-005 \mathrm{x}^{2}$ & $0,57^{* *}$ \\
$\mathrm{~K}^{(2)}$ & $\hat{y}=16,59-6,4649\left(1-\mathrm{e}^{-0,0483 \mathrm{x}}\right)$ & $0,88^{* *}$ \\
$\mathrm{Ca}^{(2)}$ & $\hat{y}=8,98+7,6024\left(1-\mathrm{e}^{-0,0507 \mathrm{x}}\right)$ & $0,90^{* *}$ \\
$\mathrm{Mg}^{(2)}$ & $\hat{y}=13,47+0,1633 \mathrm{x}-0,0006 \mathrm{x}^{2}$ & $0,77^{* *}$ \\
$\mathrm{~S}^{(2)}$ & $\hat{y}=1,93-0,1612\left(1-\mathrm{e}^{-0,0267 \mathrm{x}}\right)$ & $0,42^{* *}$ \\
$\mathrm{Cu}^{(2)}$ & $\hat{y}=\bar{y}=6,15$ & - \\
$\mathrm{Fe}^{(2)}$ & $\hat{y}=79,54+51,8184\left(1-\mathrm{e}^{-0,0454 \mathrm{x}}\right)$ & $0,64^{* *}$ \\
$\mathrm{Mn}^{(2)}$ & $\hat{y}=32,26+88,2283\left(1-\mathrm{e}^{-0,0444 \mathrm{x}}\right)$ & $0,88^{* *}$ \\
$\mathrm{Zn}^{(2)}$ & $\hat{y}=15,99+5,5688\left(1-\mathrm{e}^{-0,0616 \mathrm{x}}\right)$ & $0,74^{* *}$ \\
$\mathrm{~B}^{(3)}$ & $\hat{y}=79,98-0,0780 \mathrm{x}$ & $0,13^{*}$ \\
\hline
\end{tabular}

$* * \mathrm{e}^{*}$ significativo a 1 e $5 \%$, respectivamente. ${ }^{(1)} \mathrm{N}$ : extração por digestão sulfúrica. ${ }^{(2)} \mathrm{P}, \mathrm{K}, \mathrm{Ca}, \mathrm{Mg}, \mathrm{S}, \mathrm{Cu}, \mathrm{Zn}, \mathrm{Fe}$ e $\mathrm{Mn}$ : extração por digestão nítrico-perclórica. ${ }^{(3)} \mathrm{B}$ : extração por digestão via seca.
$\mathrm{Ca}$, de 1,1 para $\mathrm{Mg}$, de 0,17 para $\mathrm{S}$, e, em mg/planta, de 4,1 para $\mathrm{B}$, de 20,2 para $\mathrm{Fe}$, de 16,4 para $\mathrm{Mn}$ e de 2,0 para $\mathrm{Zn}$ representaram $90 \%$ dos seus máximos acúmulos. Esses resultados, nessa ordem, foram verificados com as seguintes doses de P: 32 , $61,62,37,43,76,79,72$ e $44 \mathrm{mg} \mathrm{dm}^{-3}$. O acúmulo de $\mathrm{K}$ estabilizou em 2,5 g/planta a partir da dose de $6,0 \mathrm{mg} \mathrm{dm}^{-3} \mathrm{P}$ e o de $\mathrm{Cu}$ em $0,6 \mathrm{mg} /$ planta a partir da dose de $1,0 \mathrm{mg} \mathrm{dm}^{-3} \mathrm{P}$, ou seja, praticamente não variaram em razão da adubação fosfatada.

Ao final do estudo, verificou-se acréscimo linear dos teores de $\mathrm{P}$ (máximo de $80,5 \mathrm{mg} \mathrm{dm}^{-3}$ ) e Ca (máximo de 26,2 $\mathrm{mmol}_{\mathrm{c}} \mathrm{dm}^{-3}$ ) do solo; para o teor de $\mathrm{K}$ (máximo de $1,8 \mathrm{mmol}_{\mathrm{C}} \mathrm{dm}^{-3}$ ), notou-se efeito oposto (Quadro 3). Houve aumento linear da SB (máximo de 48,9 $\mathrm{mmol}_{\mathrm{c}} \mathrm{dm}^{-3}$ ) e da CTC calculada do solo (máximo de $73,0 \mathrm{mmol}_{\mathrm{c}} \mathrm{dm}^{-3}$ ). Por causa de um ajuste quadrático, constatou-se máximo valor de $\mathrm{H}+\mathrm{Al}\left(24,9 \mathrm{mmol}_{\mathrm{c}} \mathrm{dm}^{-3}\right)$ com a dose calculada de $143 \mathrm{mg} \mathrm{dm}{ }^{-3} \mathrm{P}$ (Quadro 3). A V\% final do solo $(66,8)$, o $\mathrm{pH}(5,6)$ e os teores de $\mathrm{Cu}\left(0,50 \mathrm{mg} \mathrm{dm}^{-3}\right)$ e $\mathrm{Fe}$ $\left(25,5 \mathrm{mg} \mathrm{dm}^{-3}\right)$ não se alteraram. Os máximos teores de $\mathrm{Mn}\left(2,0 \mathrm{mg} \mathrm{dm}^{-3}\right)$ e $\mathrm{Zn}\left(2,1 \mathrm{mg} \mathrm{dm}^{-3}\right)$, entretanto, foram estimados com as doses de 148 e $114 \mathrm{mg} \mathrm{dm}^{-3} \mathrm{de}$ $\mathrm{P}$, ajustando-se a equações quadráticas (Quadro 3). 
Quadro 2. Equações de regressão referentes ao acúmulo total de N, P, K, Ca, Mg e S (g/planta) e B, Cu, Fe, Mn e Zn (mg/planta) em plantas de pinhão-manso em razão de doses de $P, 150$ dias após o transplantio

\begin{tabular}{ccc}
\hline Nutriente & Equação & $\mathbf{R}^{2}$ \\
\hline $\mathrm{N}$ & $\hat{y}=0,25+1,6789\left(1-\mathrm{e}^{-0,0714 \mathrm{x}}\right)$ & $0,91^{* *}$ \\
$\mathrm{P}$ & $\hat{y}=0,0142+0,1831\left(1-\mathrm{e}^{-0,0377 \mathrm{x}}\right)$ & $0,75^{* *}$ \\
$\mathrm{~K}$ & $\hat{y}=0,3791+2,0939\left(1-\mathrm{e}^{-1,5419 \mathrm{x}}\right)$ & $0,92^{* *}$ \\
$\mathrm{Ca}$ & $\hat{y}=0,0942+0,8646\left(1-\mathrm{e}^{-0,0372 \mathrm{x}}\right)$ & $0,90^{* *}$ \\
$\mathrm{Mg}$ & $y=0,1275+1,0461\left(1-\mathrm{e}^{-0,0619 \mathrm{x}}\right)$ & $0,90^{* *}$ \\
$\mathrm{~S}$ & $\hat{y}=0,0247+0,1565\left(1-\mathrm{e}^{-0,0535 \mathrm{x}}\right)$ & $0,85^{* *}$ \\
$\mathrm{~B}$ & $y=0,6494+3,7875\left(1-\mathrm{e}^{-0,0303 \mathrm{x}}\right)$ & $0,85^{* *}$ \\
$\mathrm{Cu}$ & $\hat{y}=0,0876+0,4783\left(1-\mathrm{e}^{-5,9232 \mathrm{x}}\right)$ & $0,65^{* *}$ \\
$\mathrm{Fe}$ & $\hat{y}=4,60+17,3725\left(1-\mathrm{e}^{-0,0293 \mathrm{x}}\right)$ & $0,86^{* *}$ \\
$\mathrm{Mn}$ & $\hat{y}=3,23+14,6396\left(1-\mathrm{e}^{-0,0318 \mathrm{x}}\right)$ & $0,88^{* *}$ \\
$\mathrm{Zn}$ & $\hat{y}=0,2352+1,9291\left(1-\mathrm{e}^{-0,0522 \mathrm{x}}\right)$ & $0,87^{* *}$ \\
\hline
\end{tabular}

** significativo a $1 \%$.

Quadro 3. Equações de regressão referentes ao valor de $\mathrm{pH}$, teor de $\mathrm{MO}, \mathrm{P}_{\text {resina }}, \mathrm{H}+\mathrm{Al}, \mathrm{K}, \mathrm{Ca}, \mathrm{Mg}, \mathrm{SB}$, CTC, V\%, B, Cu, Fe, Mn e Zn do solo ao final do experimento, em função das doses de $P$

\begin{tabular}{lll}
\hline Atributo & \multicolumn{1}{c}{ Equação } & \multicolumn{1}{c}{$\mathbf{R}^{2}$} \\
\hline $\mathrm{pH}\left(\mathrm{CaCl}_{2}\right)^{(1)}$ & $\hat{y}=\bar{y}=5,63$ & - \\
$\mathrm{MO}\left(\mathrm{g} \mathrm{dm}^{-3}\right)^{(2)}$ & $\hat{y}=\bar{y}=18,2$ & $0,93^{* *}$ \\
$\mathrm{H}+\mathrm{Al}\left(\mathrm{mmol}_{\mathrm{c}} \mathrm{dm}^{-3}\right)^{(3)}$ & $\hat{y}=18,81+0,0856 \mathrm{x}-0,0003 \mathrm{x}^{2}$ & $0,96^{* *}$ \\
$\mathrm{P}_{\text {resina }}\left(\mathrm{mg} \mathrm{dm}^{-3}\right)^{(4)}$ & $\hat{y}=0,39+0,4006 \mathrm{x}$ & $0,15^{*}$ \\
$\mathrm{~K}\left(\mathrm{mmol}_{\mathrm{c}} \mathrm{dm}^{-3}\right)^{(4)}$ & $\hat{y}=1,75-0,0031 \mathrm{x}$ & $0,71^{* *}$ \\
$\mathrm{Ca}\left(\mathrm{mmol}_{\mathrm{c}} \mathrm{dm}^{-3}\right)^{(4)}$ & $\hat{y}=19,98+0,0313 \mathrm{x}$ & - \\
$\mathrm{Mg}\left(\mathrm{mmol}_{\mathrm{c}} \mathrm{dm}^{-3}\right)^{(4)}$ & $\hat{y}=\ddot{\mathrm{y}}=20,55$ & $0,36^{* *}$ \\
$\mathrm{SB}\left(\mathrm{mmol}_{\mathrm{c}} \mathrm{dm}^{-3}\right)$ & $\hat{y}=41,53+0,0366 \mathrm{x}$ & $0,58^{* *}$ \\
$\mathrm{CTC}\left(\mathrm{mmol}_{\mathrm{c}} \mathrm{dm}^{-3}\right)$ & $\hat{y}=62,01+0,0553 \mathrm{x}$ & - \\
$\mathrm{V} \%$ & $\hat{y}=\bar{y}=66,85$ & - \\
$\mathrm{Cu}\left(\mathrm{mg} \mathrm{dm}^{-3}\right)^{(5)}$ & $\hat{y}=\bar{y}=0,50$ & - \\
$\mathrm{Fe}\left(\mathrm{mg} \mathrm{dm}^{-3}\right)^{(5)}$ & $\hat{y}=\bar{y}=25,15$ & $0,82^{* *}$ \\
$\mathrm{Mn}\left(\mathrm{mg} \mathrm{dm}^{-3}\right)^{(5)}$ & $\hat{y}=1,06+0,0131 \mathrm{x}-4,4229 \mathrm{E}-005 \mathrm{x}^{2}$ & - \\
$\mathrm{Zn}\left(\mathrm{mg} \mathrm{dm}^{-3}\right)^{(5)}$ & $\hat{y}=2,44-0,0052 \mathrm{x}+2,2857 \mathrm{E}-005 \mathrm{x}^{2}$ & $0,33^{* *}$ \\
$\mathrm{~B}\left(\mathrm{mg} \mathrm{dm}^{-3}\right)^{(6)}$ & $\hat{y}=\bar{y}=0,55$ & - \\
\hline
\end{tabular}

$* * \mathrm{e}^{*}$ significativo a 1 e $5 \%$, respectivamente. ${ }^{(1)} \mathrm{pH}$ em $\mathrm{CaCl}_{2}$. (2) MO: extração em solução sulfocrômica (Raij et al., 2001). ${ }^{(3)} \mathrm{H}+\mathrm{Al}$ : extração em acetato de cálcio $0,5 \mathrm{~mol} \mathrm{~L}^{-1} \mathrm{pH} 7,0 .{ }^{(4)} \mathrm{P}, \mathrm{K}$, Ca e Mg: extração por resina trocadora de íons em extrato de cloreto de amônio $0,2 \mathrm{~mol} \mathrm{~L}{ }^{-1} \mathrm{pH} 7,0 .{ }^{(5)} \mathrm{Cu}, \mathrm{Fe}, \mathrm{Mn}$ e $\mathrm{Zn}$ : extração em solução DTPA em pH 7,3. ${ }^{(6)}$ B: extração em água quente.

\section{DISCUSSÃO}

A importância da adubação fosfatada para o desenvolvimento inicial do pinhão-manso ficou evidenciada já nas primeiras semanas do estudo, uma vez que com a ausência unicamente do $\mathrm{P}$ (tratamento
$\mathrm{P}_{0}$ ) o desenvolvimento das mudas foi tal qual ao do tratamento-controle, sem qualquer correção ou adubação (Figura 1a,b). Isso porque o $\mathrm{P}$ faz parte da estrutura da planta e de várias moléculas-chave no seu metabolismo, compondo membranas (fosfolipídios), RNA (ácido ribonucleico), DNA (ácido desoxirribonucleico), ATP (trifosfato de adenosina) e ésteres de carboidratos, além de promover a formação de raiz e auxiliar a fixação simbiótica do N (Malavolta et al., 1997). A adubação fosfatada foi importante também para o incremento em área foliar das mudas (Figura 2c). Sabe-se que a deficiência de $\mathrm{P}$ pode diminuir a área foliar das plantas em consequência, principalmente, da redução no número de folhas e, secundariamente, da limitação à expansão da folha (Lynch et al., 1991; Rodríguez et al., 1998).

A adubação fosfatada também promoveu incremento de MS de folhas, caules e pecíolos, raiz e MS total (Figura 3). A importância desse nutriente para o incremento de biomassa também foi constatado por Silva et al. (2009), cuja pesquisa com omissão de $\mathrm{P}$ apontou redução de 68 \% na produção de MS total de mudas de pinhão-manso. Neste estudo, a dose de $57 \mathrm{mg} \mathrm{dm}^{-3}$ de $\mathrm{P}$ contempla a necessidade de P para o incremento de MS total e de todas as outras características avaliadas. Essa dose é semelhante daquela indicada por Souza et al. (2011), que recomendaram $55 \mathrm{mg} \mathrm{dm}^{-3}$ de $\mathrm{P}$ para $\mathrm{o}$ desenvolvimento inicial do pinhão-manso.

Os teores foliares dos macronutrientes $\mathrm{P}, \mathrm{K}, \mathrm{Ca}$, $\mathrm{Mg}$ e S aumentaram exponencialmente (Quadro 1) em razão da adubação fosfatada. Lima et al. (2011a) também verificaram que a adubação com $\mathrm{P}$ promoveu aumento dos teores de $\mathrm{P}, \mathrm{K}, \mathrm{Mg}$ e $\mathrm{S}$ nos tecidos da parte aérea de mudas de pinhão-manso. É importante considerar que ainda não foi estabelecido o teor adequado de cada nutriente e nem a folha para determinar a diagnose nutricional do pinhão-manso. Além disso, o teor foliar dos elementos é influenciado por vários fatores, como: solo, adubação, correção de acidez, variedade da planta, folha e parte da folha, clima, práticas culturais, pragas e doenças (Malavolta, 2006). Laviola \& Dias (2008) estudaram o teor de nutrientes em folhas completamente expandidas de pinhão-manso (entre a $6^{\mathrm{a}}$ e $7^{\mathrm{a}}$ abaixo da inflorescência), cultivado em campo, e verificaram teores próximos aos apresentados neste estudo, exceto para $\mathrm{Mg}, \mathrm{B}$ e Mn.

Lima et al. (2011b) estudaram a posição da folha no ramo secundário e o tipo de ramo (vegetativo ou florífero) para diagnosticar o estádio nutricional de plantas de pinhão-manso e constataram que as folhas, apenas as completamente expandidas, das posições 2 e 3 a partir do ápice são as mais adequadas para análise foliar de N, P, K, S, Cu, Fe, Mn e Zn. Os autores concluíram ainda que as folhas nas posições 5 ou 10 são mais apropriadas para avaliação de Ca e Mg e que o estádio fenológico do ramo pode influenciar nos teores de nutrientes. Os teores foliares de $\mathrm{P}\left(2,1 \mathrm{~g} \mathrm{~kg}^{-1}\right)$ e S 
$\left(1,8 \mathrm{~g} \mathrm{~kg}^{-1}\right)$ (Quadro 1) foram os que mais se aproximaram dos obtidos por Lima et al. (2011b), o que sugere que o teor de tais nutrientes não apresenta variações significativas entre folhas de posição distintas na planta. Além disso, Souza et al. (2011) encontraram teor de $\mathrm{P}$ de $2,1 \mathrm{~g} \mathrm{~kg}^{-1}$ na parte aérea de mudas de pinhão-manso. Com esse resultado, pode-se confirmar que a variação do teor de $\mathrm{P}$ é pequena entre distintas partes da planta de pinhão-manso em início de desenvolvimento.

$\mathrm{O}$ acúmulo total de nutrientes nas plantas de pinhão-manso, independentemente da dose de $\mathrm{P}$, apresentou a seguinte ordem: $\mathrm{K}>\mathrm{N}>\mathrm{Mg}>\mathrm{Ca}>\mathrm{P}>\mathrm{S}>\mathrm{Fe}>$ $\mathrm{Mn}>\mathrm{B}>\mathrm{Zn}>\mathrm{Cu}$. Laviola \& Dias (2008) verificaram que a ordem de acúmulo de nutrientes em folhas de pinhãomanso no estádio de desenvolvimento de frutos foi $\mathrm{N}>\mathrm{K}>\mathrm{Ca}>\mathrm{Mg}>\mathrm{P}>\mathrm{Mn}>\mathrm{Fe}>\mathrm{B}>\mathrm{Zn}>\mathrm{Cu}$, ordem essa que também aponta o $\mathrm{N}$ e o $\mathrm{K}$ como os mais absorvidos (extraídos). Os autores constataram que na fase em que a planta inicia sua produção há aumento da exigência por K, pois a deposição de biomassa nos frutos de pinhão-manso é acompanhada pelo acúmulo desse nutriente. Com relação ao $\mathrm{P}$, esse foi o quinto nutriente mais extraído, tanto no estudo de Laviola \& Dias (2008), que avaliaram o acúmulo de nutrientes somente pelas folhas e em fase produtiva do pinhão-manso, quanto nesta pesquisa, em que se avaliou o acúmulo total na planta em fase de muda.

Em relação à análise final do solo (Quadro 3), o aumento linear do teor de $\mathrm{P}$ era esperado em razão da adição de $\mathrm{P}$ pelos tratamentos. Entretanto, o acréscimo do teor de Ca e decréscimo do teor de K provavelmente ocorreram por causa da competição entre Ca e K nos sítios de adsorção do solo (Malavolta, 2006). Assim, a elevação linear da SB possivelmente ocorreu em razão do aumento do Ca ter sido maior que a redução do K no solo, uma vez que o teor de Mg manteve-se constante. Com o aumento da $\mathrm{SB}$ e do $\mathrm{H}+\mathrm{Al}$, houve, consequentemente, elevação linear da CTC calculada do solo. Além disso, como a $\mathrm{SB}$ e $\mathrm{H}+\mathrm{Al}$ aumentaram proporcionalmente, a $\mathrm{V} \%$ final do solo não se alterou. $\mathrm{O} \mathrm{pH}$ do solo também não variou e, por consequência, os teores de $\mathrm{MO}$ e B também não variaram, haja vista que o $\mathrm{pH}$ influencia na mineralização da $\mathrm{MO}$, que é a fonte primária de B (Malavolta, 2006).

\section{CONCLUSÕES}

1. A falta da adubação fosfatada é tão limitante ao crescimento inicial do pinhão-manso quanto a ausência simultânea da adubação e correção do solo.

2. A dose de $57 \mathrm{mg} \mathrm{dm}^{-3} \mathrm{P}$ é a mais indicada para o desenvolvimento inicial do pinhão-manso.

3. O acúmulo total de nutrientes nas mudas de pinhão-manso apresentou a seguinte ordem: $\mathrm{K}>\mathrm{N}>\mathrm{Mg}>\mathrm{Ca}>\mathrm{P}>\mathrm{S}>\mathrm{Fe}>\mathrm{Mn}>\mathrm{B}>\mathrm{Zn}>\mathrm{Cu}$.

\section{AGRADECIMENTO}

À Fundação de Amparo à Pesquisa do Estado de São Paulo (FAPESP), pela concessão da bolsa de mestrado à primeira autora.

\section{LITERATURA CITADA}

ARRUDA, F.P.; BELTRÃO, N.E.M.; ANDRADE, A.P.; PEREIRA, W.E. \& SEVERINO, L.S. Cultivo de pinhãomanso (Jatropha Curcas L.) como alternativa para o semi-árido nordestino. R. Bras. Oleag. Fibr., 8:789-799, 2004.

BHERING, L.L.; LAVIOLA, B.G.; SALGADO, C.C.; SANCHEZ, C.F.B.; ROSADO, T.B. \& ALVES, A.A. Genetic gains in physic nut using selection indexes. Pesq. Agropec. Bras., 47:402-408, 2012.

BUWALDA, J.C. \& GOH, K.M. Host-fungus competition for carbon as a cause of growth depressions in vesiculararbuscular mycorrhizal ryegrass. Soil Biol Biochem., 14:103-106, 1982.

EMPRESA BRASILEIRA DE PESQUISA AGROPECUÁRIA EMBRAPA. Centro Nacional de Pesquisa do Solo. Sistema brasileiro de classificação de solos. Brasília, 2006. 412p.

FERNANDES, J.D.; CHAVES, L.H.G.; DANTAS, J.P. \& SILVA, J.R.P. Fenologia e produção do pinhão-manso cultivados com diferentes fontes de adubação. R. Ci. Agron., 44:339346, 2013.

JESCHKE, W.D.; PEUKE, A.; KIRKBY, E.A.; PATE, J.S. \& HARTUNG, W. Effects of P deficiency on the uptake, flows and utilization of $\mathrm{C}, \mathrm{N}$ and $\mathrm{H}_{2} \mathrm{O}$ within intact plants of Ricinus communis L. J. Exp. Bot., 47:1737-1754, 1996.

LAVIOLA, B.G. \& DIAS, L.A.S. Teor e acúmulo de nutrientes em folhas e frutos de pinhão-manso. R. Bras. Ci. Solo, 32:1969-1975, 2008.

LIMA, R.L.S.; SEVERINO, L.S.; GHEYI, H.R.; SOFIATTI, V. \& ARRIEL, N.H.C. Efeito da adubação fosfatada sobre o crescimento e teor de macronutrientes de mudas de pinhão manso. R. Ci. Agron., 42:950-956, 2011a.

LIMA, R.L.S.; SEVERINO, L.S.; CAZETTA, J.O.; AZEVEDO, C.A.V.; SOFIATTI, V. \& ARRIEL, N.H.C. Posição da folha e estádio fenológico do ramo para análise foliar do pinhãomanso. R. Bras. Eng. Agric. Amb., 15:1068-1072, 2011b.

LYNCH, J.; LÄUCHLI, A. \& EPSTEIN, E. Vegetative growth of the common bean in response to phosphorus nutrition. Crop Sci., 31:380-387, 1991.

MALAVOLTA, E. Manual de nutrição mineral de plantas. São Paulo, Agronômica Ceres, 2006. 638p.

MALAVOLTA, E.; VITTI, G.C. \& OLIVEIRA, S.A. Avaliação do estado nutricional das plantas: Princípios e aplicações. 2.ed. Piracicaba, Associação Brasileira para Pesquisa da Potassa e Fosfato, 1997. 201p. 
MARSCHNER, H. Mineral nutrition of higher plants. London, Academic Press, 1995. 889p.

MENGEL, K. Responses of various crop species and cultivars to fertilizer application. Plant Soil, 72:305-319, 1983.

NOVAIS, R.F.; NEVES, J.C.L. \& BARROS, N.F. Ensaio em ambiente controlado. In: OLIVEIRA, A.J.; GARRIDO, W.E.; ARAÚJO, J.D. \& LOURENÇO, S., eds. Métodos de pesquisa em fertilidade do solo. Brasília, Embrapa-SEA, 1991. p.189-254.

NOVAIS, R.F. \& SMYTH, T.J. Fósforo em solo e planta em condições tropicais. Viçosa, MG, Universidade Federal de Viçosa, 1999. 300p.

NUÑEZ-COLÍN, C.A. \& GOYTIA-JIMÉNEZ, M.A. Distribution and agroclimatic characterization of potential cultivation regions of physic nut in Mexico. Pesq. Agropec. Bras., 44:1078-1085, 2009.

PENG, S.; EISSENSTAT, D.M.; GRAHAM, J.H.; WILLIAMS, K. \& HODGE, N.C. Growth depression in mycorrhizal citrus at high-phosphorus supply. Plant Physiol., 101:1063-1071, 1993.

PRATES, F.B.S.; LUCAS, C.S.G.; SAMPAIO, R.A.; BRANDÃO JÚNIOR, D.S., FERNANDES, L.A. \& JUNIO, G.R.Z. Crescimento de mudas de pinhão-manso em resposta a adubação com superfosfato simples e pó-de-rocha. R. Ci. Agron., 43:207-213, 2012.
RAIJ, B.van; ANDRADE, J.C.; CANTARELLA, H. \& QUAGGIO, J.A. Análise química para avaliação da fertilidade de solos tropicais. Campinas, Instituto Agronômico, 2001. 285p.

RAMOS JÚNIOR, E.R.; MACHADO, R.A.F.; OLIBONE, D.; CASTOLDI, G. \& RAMOS, B.M. Crescimento de plantas de cobertura sob déficit hídrico. Semina, 34:47-56, 2013.

RODRÍGUEZ, D.; KELTJENS, W.G. \& GOUDRIAAN, J. Plant leaf area expansion and assimilate production in wheat (Triticum aestivum L.) growing under low phosphorus conditions. Plant Soil, 200:227-240, 1998.

ROGGATZ, U.; MCDONALD, A.J.S.; STADENBERG, I. \& SCHURR, U. Effects of nitrogen deprivation on cell division and expansion in leaves of Ricinus communis L.. Plant Cell Environ., 22:7140-7791, 1999.

SILVA, E.B.; TANURE, L.P.T.; SANTOS, S.R. \& RESENDE JÚNIOR, P.S. Sintomas visuais de deficiências nutricionais em pinhão-manso. Pesq. Agropec. Bras., 44:392-397, 2009.

SOUZA, P.T.; SILVA, E.B.; GRAZZIOTTI, P.H. \& FERNANDES, L.A. NPK fertilization on initial growth of physic nut seedlings in Quartzarenic Neossol. R. Bras. Ci. Solo, 35:559-566, 2011.

TORRES, C.M.M.E.; JACOVINE, L.A.G.; TOLEDO, D.P.; SOARES, C.P.B.; RIBEIRO, S.C. \& MARTINS, M.C. Biomass and carbon stock in Jatropha curcas L. Cerne, 17:353-359, 2011. 